\title{
A large and a small hand
}

Published at www.cmaj.ca on Mar. 17

I work in a rural practice. Tucked away at the point where Highway 11 stops going north and heads west is my town: Cochrane, Ontario.

I haven't always been here. Until September 2009, I was working as a hospitalist at the Peter Lougheed Centre in Calgary, Alberta.

My new practice is full of lovely, enthusiastic people. The physicians I work with are dedicated, smart and friendly. We have a clinic and a hospital with a surgery. We take turns as emergency call and doing surgical assists. Some of us deliver babies.

It's busy and rewarding. But, the practice has run along without much change for the past 30 years, and now we're transitioning to a family health team. One of the implications of this is that we have to adopt electronic medical records.

Coming from Calgary, where I worked with Sunrise Clinical Systems in the hospital and any of a dozen or so electronic medical record systems in various clinics, I had never experienced a truly paper-based practice. This place has killed millions of acres of trees. The only way we could be less computerized is if we chiselled our prescriptions into stone tablets.

Some examples?

Every morning our receptionist copies by hand my patient list from "The Big Book" where she keeps track of our daily duties. Really, she hand copies it!

Patients come in with lists of medications and I spend most of the appointment time copying them onto paper prescription pads (sometimes two or three pages worth) to renew them.

When I get an abnormal lab result, I call for a chart, which is usually 300 or more pages. I leaf through it looking

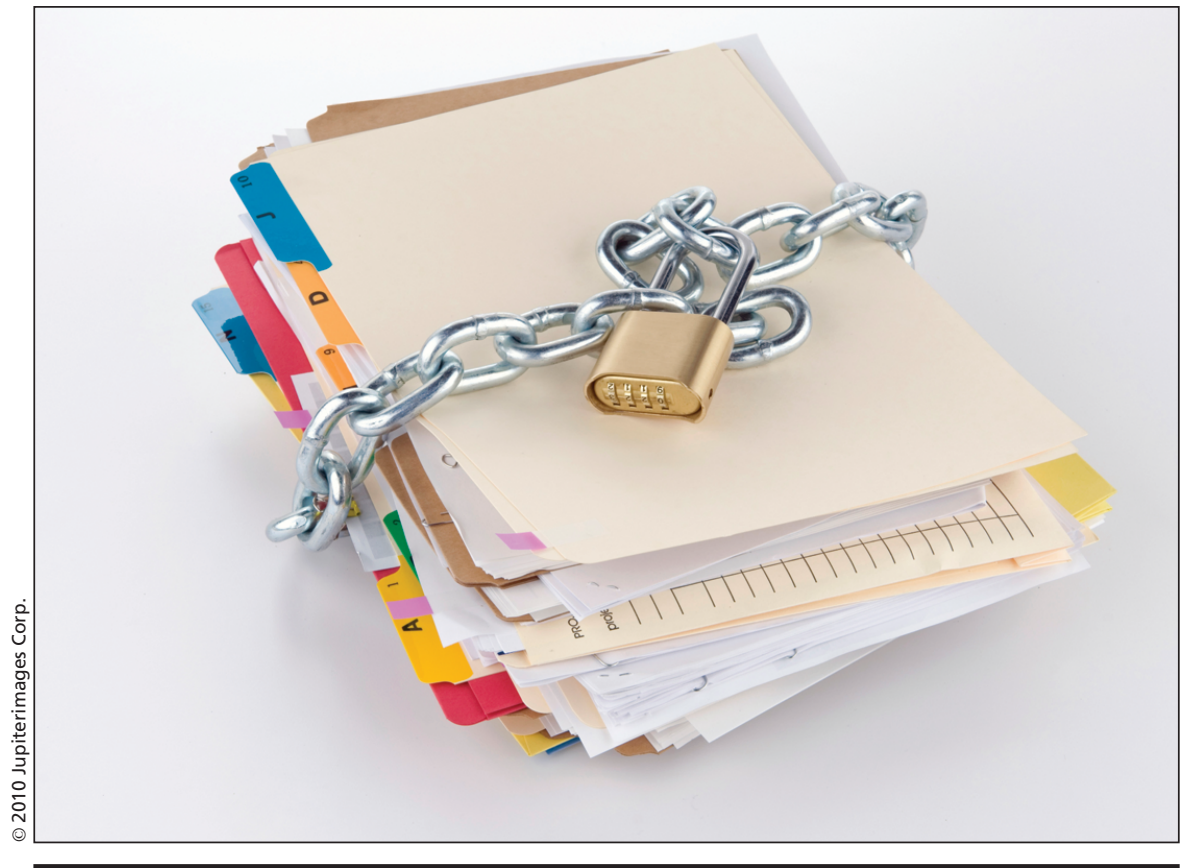

Technology alters medical practice — for the better, argues Dr. Basia Siedlecki.

for a trend. I get a handwritten cheque every month for my emergency shifts from the hospital.

My right hand is now about $30 \%$ larger than my left from writing progress notes. My handwriting is a barely legible scrawl, and degrading daily.

Being a technophile, I feel lost and adrift in the sea of paper. I keep my iPhone close just for security, like a life jacket. I'm afraid I'm going to drown in the past.

So for me, electronic medical records are a light at the end of the tunnel. I've taken on the project as my own. I'm inviting vendors, planning demonstrations and coordinating schedules so we can all be there. I order food to entice my colleagues to come they're suckers for free ribs.

I know from my work in the past that technology will change how we do things. It will change the jobs people do. "The Big Book" will disappear. Everyone will need to learn to type, and my hands will once again be similar in size.

Some people will change and some will not be able to. My hope is that, in the end, the technology itself will be a team-building exercise that will help us truly function as a family health team. — Basia Siedlecki MD, Cochrane, Ont.

DOI:10.1503/cmaj.109-3209

CMAJ invites contributions to "Dispatch from the medical front," in which physicians and other health care providers offer eyewitness glimpses of medical frontiers, whether defined by location or intervention. Submissions, which must run a maximum 700 words, should be forwarded to: wayne .kondro@cmaj.ca 